\title{
Hepatic and renal complications arising from accidental carbon tetrachloride poisoning in the human subject
}

\author{
W. C. ALSTON \\ From the Department of Biochemistry, Western Infirmary, Glasgow
}

SYNOPSIS A young man, who was admitted to hospital acutely ill following the ingestion? of half a mouthful of carbon tetrachloride, was investigated for the degree and duration of hepatic and renal damage, using various tests of function. On the basis of the serum bilirubin and enzyme activities, the acute hepatic damage had subsided after 15 days from the time of the accident, but the serum albumin and total proteins returned to normal only after a con- $\vec{\theta}$ siderably longer time interval (between 33 and 129 days). There was no evidence of residual hepatic damage after this time.

Acute renal damage reached a maximum about a week after the accident, and recovery of function in respect of the kidneys' power to reabsorb sodium and chloride and to secrete potassium and acid recovered almost completely after three weeks. However, the power of the kidneys $\stackrel{\varnothing}{\varnothing}$ to reabsorb water, ie, to produce a concentrated urine, approached normal only after $139 \overrightarrow{\overrightarrow{0}}$ days. Residual renal damage was not evident after this time interval as indicated by the clear- 3 ance values for creatinine and inorganic phosphate. The significance of the results is discussed.

Carbon tetrachloride poisoning may occur by inhalation of the vapour or by accidental ingestion. The first symptoms after ingestion are referable to the central nervous system and gastrointestinal tract, ie, dizziness, headache, vomiting, and diarrhoea. Hepatic involvement with jaundice and dark urine is usually manifest within two to four days in the more severe cases, and renal damage indicated by oliguria and proteinuria may also be evident by the same time (Zimmerman, 1963). The mortality from carbon tetrachloride poisoning was formerly high, mainly due to renal failure. However, since the introduction of efficient dialysis treatment, the prognosis has been greatly improved (Nielsen and Larsen, 1965). A unique opportunity was presented for the investigation of a human subject with respect to the acute metabolic effects of carbon tetrachloride poisoning by the admission to the Western Infirmary, Glasgow, of a patient who had ingested about half a mouthful 36 hours previously.

\section{Case Report}

A young man of 34 years was admitted to a 을 medical unit of the Western Infirmary complaining of severe, constant epigastric pain, persistent vomiting, and diarrhoea following the accidental ingestion from a lemonade bottle of about half ${ }^{\mathrm{N}}$ a mouthful of carbon tetrachloride. On admission, $\mathbb{O}$ which was on the second day after the accident, he was noticed to be slightly jaundiced and had proteinuria. On the following day he had an attack of epistaxis and subsequently he developed ${ }_{\Phi}$ haematuria on the ninth, 10th, and 12th days $\stackrel{?}{?}$ after exposure. Oliguria was already evident on 0 admission, and the 24-hour urine volume dropped ${ }_{0}$ to a minimum on the fifth day after exposure.

The patient was treated by fluid restriction $\stackrel{\mathbb{D}}{\circ}$ and an acute Giovannetti diet ( $2.6 \mathrm{~g}$ nitrogen, $\frac{\sigma}{\sigma}$ 9 m-equiv sodium, and 15 m-equiv potassium per day). In spite of these conservative measures, $\delta$ the blood urea level continued to rise and Received for publication 1 July 1969. 


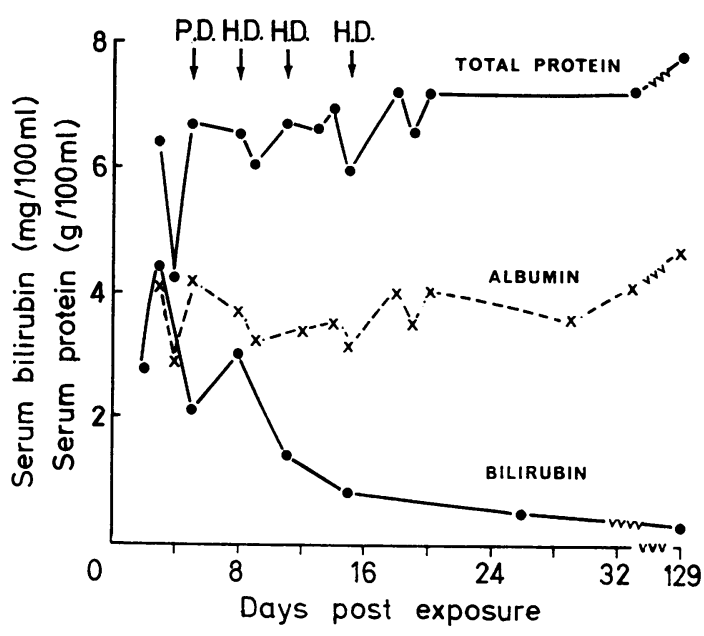

Fig. 1a Serial changes in the patient's serum total protein, albumin, and total bilirubin. $P D=$ peritoneal dialysis $H D=$ haemodialysis .

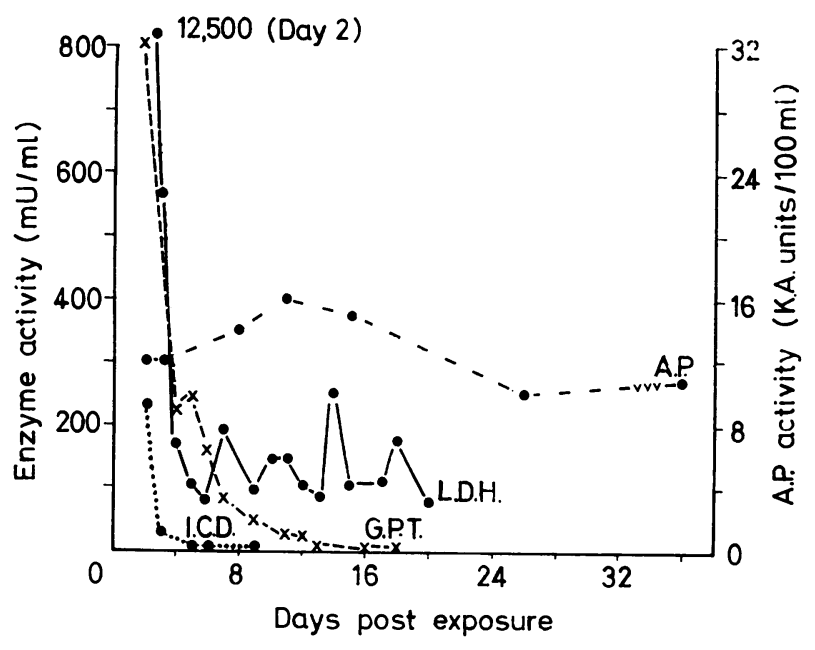

Fig. 1b Serial changes in the patient's serum activity of several enzymes.

peritoneal dialysis was initiated on the fifth day after exposure. However, the blood urea level still continued to rise and his general condition deteriorated until on the eighth day he developed the signs of left ventricular failure. Haemodialysis was performed and the following day he was much improved. His general condition continued to improve and he required only two subsequent haemodialyses on the 11 th and 15 th days after exposure. On the 18th and 19th days, diuresis started and the patient's dietary protein was then increased to $\mathbf{4 0} \mathrm{g}$ per day. His genera $\bar{P}$ condition continued to improve and he was discharged well on the 31 st day after exposure.

\section{Materials and Methods}

All serum analyses were carried out on un haemolysed specimens, and where determinations were not carried out immediately, eg, in the case of enzymes, the serum was stored at $-20^{\circ} \mathrm{Co}$ Urine was collected for 24-hour periods, no preservative being added since the urine wa乡 analysed forthwith, or aliquots were kept at $-20^{\circ} \mathrm{C}$ until determinations could be made Standard AutoAnalyzer (Technicon ${ }^{1}$ ) methods़ were used to determine sodium, potassium $\omega$ chloride, total carbon dioxide (expressed as bicarbonate), urea, creatinine, total bilirubine serum albumin (bromocresol green method), and total proteins (biuret method). Estimation $\overrightarrow{\$}$ of urine urea and creatinine were made usin suitable dilutions, and of urine electrolytes using the method of Michael (1966). Urine chloride्, was estimated by the method of Schales an $\$$ Schales (1941), and urine protein by the method of Bell and Baron (1968). Titratable acidity was determined by titrating a $10 \mathrm{ml}$ aliquot of th 24-hour urine collection with $0.05 \mathrm{~N}$ sodiun\$ hydroxide to $p \mathrm{H} 7 \cdot 4$ using a $p \mathrm{H}$ meter ${ }^{2}$. Uring specific gravity was measured by very accuratel weighing $10 \mathrm{ml}$ samples of urine on an Oertling balance. Glucose in urine was tested for using Clinistix test papers. Inorganic phosphate was determined both in serum and urine (diluted 1 in 100) by the method of Fiske and Subbarow (1925).

Alkaline phosphatase, which is normally. present in serum within the range 4 to $12 \mathrm{King}$ Armstrong units per $100 \mathrm{ml}$, was determined bo a standard AutoAnalyzer method using disodiun? phenyl phosphate as substrate. Serum alanines aminotransferase (GPT) was determined using a special $\mathrm{kit}^{3}$. The normal value for GPT in serum is up to $12 \mathrm{mU}$ per ml. Lactate dehydrogenase (LDH) activity was determined by the method of Wrobleswki and LaDue (1955) and hydroxybutyrate dehydrogenase (HBD) by the method of Elliot and Wilkinson (1961). The latter authors gave the normal range for LDF activity as 72 to $240 \mathrm{mU}$ per $\mathrm{ml}$ and for HBD as 56 to $125 \mathrm{mU}$ per ml serum. Isocitrate dehydro=0 genase (ICD) was determined by the colorimetrie method of Bell and Baron (1960), the norma\$ range being 1 to $3 \mathrm{mU}$ per $\mathrm{ml}$. Glutamat dehydrogenase (GD) was determined by the method described by Schmidt (1963). This

${ }^{1}$ Technicon Instruments Co. Ltd, Chertsey, Surrey, England. ${ }^{2}$ Electronic Instruments Ltd, Richmond, Surrey, England. ${ }^{3}$ C. F. Boehringer \& Sähne, GMBH, Mannheim, Germany. 


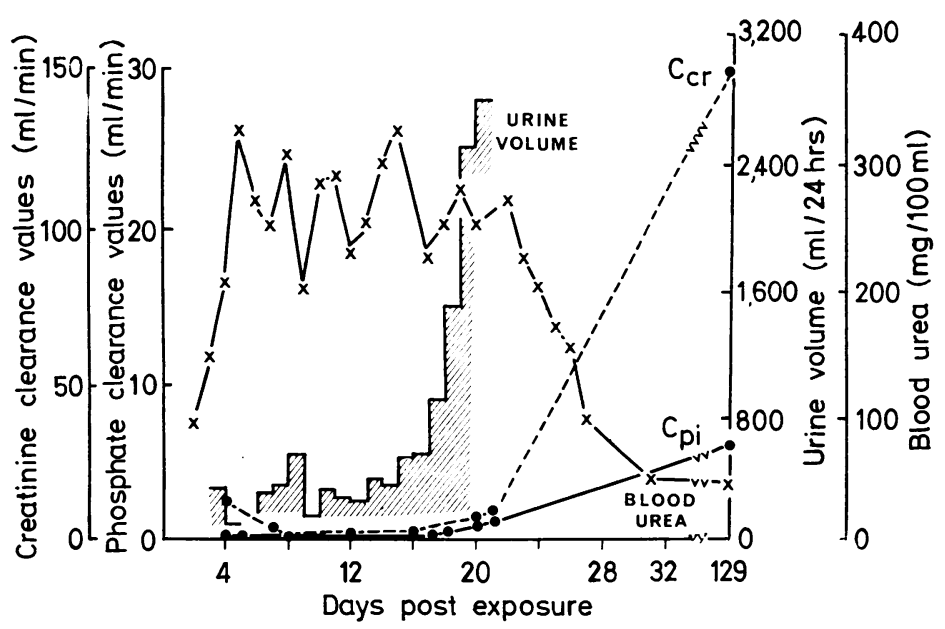

Fig. 1c Serial changes in the patient's 24-hour urine volume, blood urea, and in the clearance values for creatinine and inorganic phosphate.

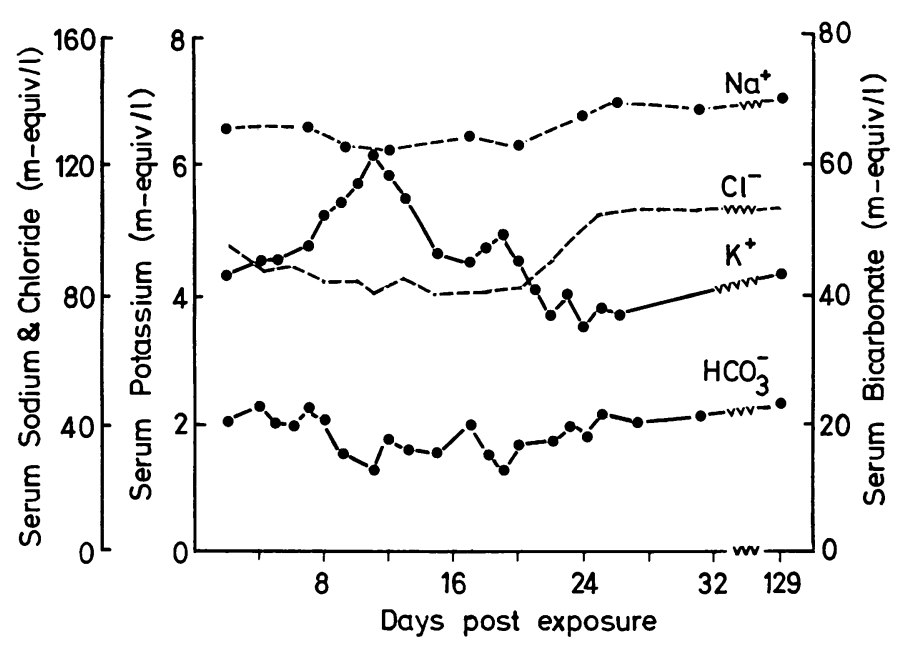

Fig. 1d Serial changes in the patient's serum level for sodium, potassium, chloride, and bicarbonate.

enzyme is confined to the mitochondria of cells and is not normally present in serum above the level of $0.9 \mathrm{mU}$ per $\mathrm{ml}$.

\section{Results}

In order to achieve a meaningful discussion of the results of the investigation, it was considered

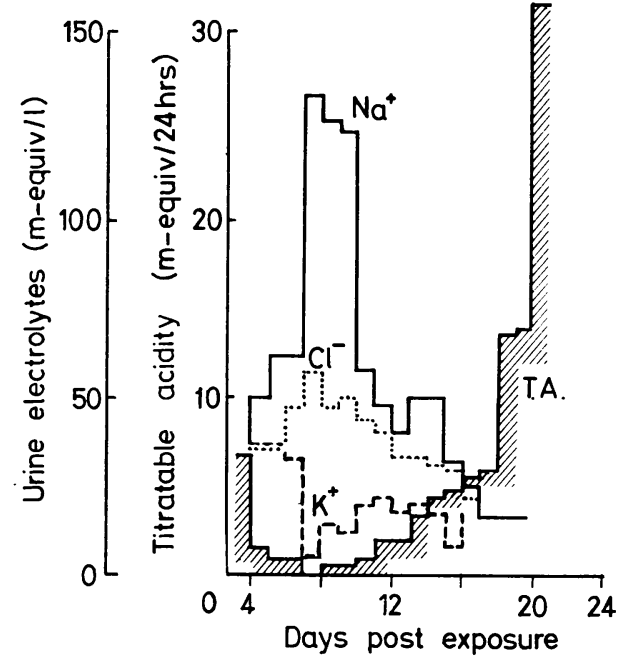

Fig. 1e Serial changes in the patient's urinary concentration of sodium, potassium, and chloride and in the urine titratable acidity.

that all measurements should be referred to the day of the accident rather than to the day of admission. Consequently, all results are related to days after exposure in the figures and in the discussion. Figure 1a shows graphically the changes which occurred in serum total proteins, albumin, and bilirubin, and Fig. 1b shows the alterations in the serum activities of several enzymes which are known to increase in serum after carbon tetrachloride administration to experimental animals (Rouiller, 1964). It was also found that the level of glutamate dehydrogenase was greatly raised on the second day, ie, 120 units $/ \mathrm{ml}$, the activity disappearing by the fifth day. Clotting time was very markedly decreased between the second and eighth days (communication from Haematology Department), which would account for the episodes of epistaxis on the third day and the episodes of haematuria.

Figure 1c shows the course of the patient with $N$ regard to urine output, blood urea, and the $N$ clearance values for creatinine and inorganic $N$ phosphate, and Figs. 1d and 1e present the details of the disordered electrolyte and acid-base balance. Also found but not reported in the figures was glucosuria until about the 16th day and proteinuria which reached a maximum of about $1.5 \mathrm{~g}$ per $100 \mathrm{ml}$ on the eighth day. The urine specific gravity was reduced to 1.008 by the fifth day and remained at about the same level for the three weeks of observation.

When the patient was seen at a follow-up clinic on the 129th day, he was clinically well. \& The serum bilirubin and proteins were within normal limits, the serum electrolytes were normal, and the clearance value of creatinine was $148 \mathrm{ml} \rightleftharpoons$ 
per minute and of inorganic phosphate $30 \mathrm{ml}$ per minute. Microscopic examination of the urinary sediment did not reveal the presence of cellular or protein casts or red blood cells. The urine specific gravity was 1.015 and on the 139th day had increased further to 1.019.

\section{Discussion}

It is to be expected that, with oral intake, the signs and symptoms of acute gastrointestinal irritation would be the presenting features, and, in view of the rapid absorption of the halocarbon, liver damage would be manifest very quickly. Already, on the second day, the activities of most of the enzymes were enormously raised indicating that hepatocytes had already been severely damaged. Damage to the biliary system was slight, there being only a temporary increase in the serum bilirubin and alkaline phosphatase values with a return towards normal by the 15 th day. The rate of decline of the enzyme activities in serum showed some interesting differences. Isocitrate dehydrogenase had reached normal levels by the sixth day while GPT only returned to within the normal range by the 13th day. Lactate dehydrogenase, on the other hand, apparently reached normal levels by the sixth day followed by a secondary irregular rise until the 18th day. The ratio of LDH to HBD activity on day 2 was $4 \cdot 3$, indicating that the source of the enzyme was mainly, if not entirely, liver at this stage. However, another possibility has to be considered concerning the persistent elevation of the serum LDH and GPT activities. Kemp, Lange, Laursen, and Nielsen (1964) have reported an appreciably increased serum LDH and also GPT activity in cases of acute renal tubular necrosis of multiple aetiology. These increases in enzyme activity were most striking during the first seven to 10 days of anuria, and isoenzyme studies seemed to indicate that, at least in the case of LDH, the enzyme was derived mainly from the damaged kidneys. It could be that the changes reported here are compounded by enzymes liberated from damaged liver and kidneys, the contribution from the liver perhaps preponderating in the early stages.

The acute decrease in serum albumin, total proteins, and clotting time is understandable in terms of the known effect of carbon tetrachloride on the protein synthetic machinery of the liver (Schmuckler, Iseri, and Benditt, 1962). The fact that the serum levels of albumin and total proteins had not returned to normal by three weeks may be partly due also to the restricted protein intake and the effects of uraemia.

Although the patient was already oliguric on admission, it is clear that the renal damage leading to the episode of acute renal failure was much more insidious in its development than in the case of the hepatic damage. By the eighth day, urine protein concentration was maximal, titratable acidity zero, and the urine secreted rep? resented almost unmodified glomerular filtrate iz respect of its electrolyte concentration and $p \mathrm{H}^{\mathrm{w}}$ As with the four cases reported by Sirota (1949) the power to reabsorb chloride was retained to a greater extent than that of the other electrolyte during the phase of injury. Sirota found litt depression of acid-secreting power in his case On the other hand, the patient reported here was. more severely affected, as indicated by the much greater loss of protein, glucose, and eventualo red blood cells in the urine. Concentrating powes had not begun to recover by the time of the patient's discharge from the hospital.

In the initial stages, following the poisoning if the case reported, the renal tubules were stif responding (although with diminishing efficiency to bodily needs by concentrating the urine an£p secreting acid. However, damage progressef rapidly, and probably an abnormally increase 8 glomerular permeability allowed the escape of protein and red blood cells as well as the normal constituents of the glomerular fluid. It is nots possible, on the basis of the present findings, say that the site of the lesion was confined to one segment of the nephron. The increased loss of electrolytes and glucose would seem to be associated with damage to the proximal tubulf whereas the loss of acid-secreting power woul indicate injury to the distal tubule. The very low clearance values for creatinine and inorgani phosphate are almost certainly associated with tubular damage and back-diffusion of th glomerular filtrate through the damaged tubules As found also by Sirota, the beginning of diuresis is accompanied by little change in the serum levels of urea and creatinine, and with only. minimal changes in the clearances of creatinine and inorganic phosphate, suggesting a restoratio of the 'tubular barrier' of the urinary 'conduits with no improved reabsorptive capacity for wate?

Sirota found in his most severely affected patient that the creatinine clearance had reached the lower limit of normal by the 175th day, but in the case reported here, it was already quite. normal by the 129th day. If any residual damages was present in the kidneys at this time, the cleatis ances of creatinine and inorganic phosphate an the normal serum electrolytes indicate that hyperfunction of the remaining nephrons ha completely compensated for any that had beeq irretrievably damaged.

I wish to thank Dr A. L. Linton for granting pero mission to publish these results from the patient, who was under his care. It is a pleasure also to than Dr E. B. Hendry for his encouragement and helpf criticism of the manuscript and also my colleagues. who performed some of the chemical analyses. 


\section{References}

Bell, J. L., and Baron, D. N. (1960). A colorimetric method for determination of isocitric dehydrogenase. Clin. chim. Acta, 5, 740-747.

Bell, J. L., and Baron, D.N. (1968). Quantitative biuret determination of urine protein. Proc. Ass. clin. Biochem., 5, 63-64.

Elliott, B. A., and Wilkinson, J. H. (1961). Serum ' $a$-hydroxybutyric dehydrogenase' in myocardial infarction and in liver disease. Lancet, 1, 698-699.

Fiske, C. H., and Subbarow, Y. (1925). The colorimetric determination of phosphorus. J. biol. Chem., 66, 375-400.

Kemp, E., Lange, H., Laursen, T., and Nielsen, V. K. (1964). Elevated serum enzyme activity in acute renal failure. Proc. Europ. Dialysis Transplant Ass., 1, 135-137.

Michael, C. (1966). AutoAnalyzer Development Sheet. Technicon Instrument Co. Chertsey, Surrey.

Nielsen, V. K., and Larsen, J. (1965). Acute renal failure due to carbon tetrachloride poisoning. Acta med. scand., 178, 363-374.
Rouiller, Ch. (1964). Experimental toxic injury of the liver. In $C$ The Liver, edited by $\mathrm{Ch}$. Rouiller, vol. 2, pp. 335-476 Academic Press, New York and London.

Schales, O., and Schales, S. S. (1941). A simple and accurate method for the determination of chloride in biological fluids. J. biol. Chem., 140, 879-884.

Schmidt, E. (1963). In Methods of Enzymatic Analysis, pp. 752 756, edited by H. U. Bergmeyer. Academic Press, New York and London.

Sirota, J. H. (1949). Carbon tetrachloride poisoning in man. I. The mechanisms of renal failure and recovery. $J$. clin. Invest., 28, 1412-1422.

Smuckler, E. A., Iseri, O. A., and Benditt, E. P. An intracellular defect in protein synthesis induced by carbon tetrachloride. J. exp. Med., 116, 55-71.

Wróblewski, F., and LaDue, J. S. (1955). Lactic dehydrogenase activity in blood. Proc. Soc. exp. Biol. (N.Y.), 90, 210-213.

Zimmerman, H. J. (1963). Clinical and laboratory manifestations of hepatotoxicity. Ann. N.Y. Acad. Sci., 104, 954-987. 